\section{A forward-pulling technique for complicated Trapezoid basket impaction during retrieval of common bile duct stones}

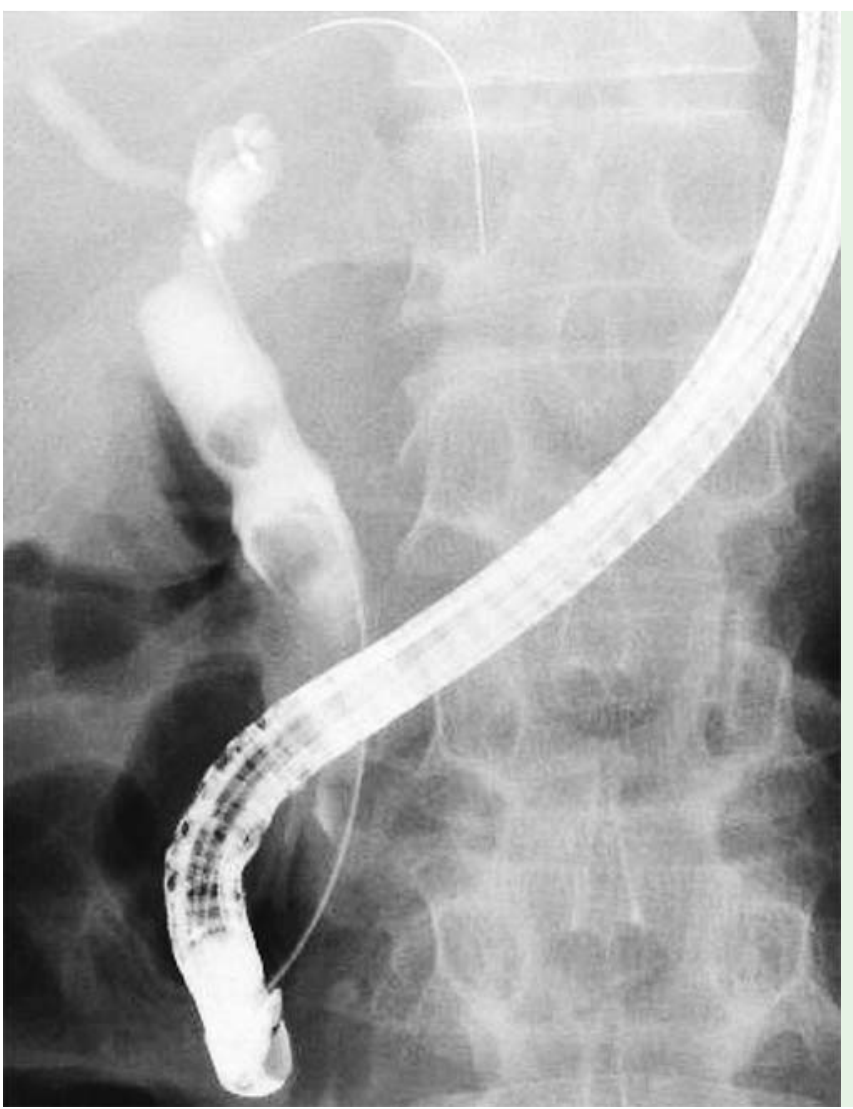

Fig. 1 Endoscopic retrograde cholangiography revealing multiple common bile duct stones.

Although basket impaction rarely occurs during retrieval of common bile duct stones, it is a potentially serious event [1]. The Trapezoid RX wire-guided retrieval basket (Boston Scientific Corp., Marlborough, Massachusetts, USA) has an emergency release feature, whereby the tip is designed to disengage, thereby facilitating basket removal and reducing the risk of impaction [2]. However, we encountered a rare case of trapezoid basket impaction that was complicated by difficulties in detaching the outer sheath from the basket wires.

A man in his 50s was admitted with multiple common bile duct stones ( $\mathbf{F i g . 1}$ ). After endoscopic sphincterotomy and endoscopic papillary large-balloon dilation, mechanical lithotripsy was attempted using a Trapezoid basket. However, basket impaction occurred because the stone was too hard and the tip of the Trapezoid failed to disengage.
We attempted to remove the duodenoscope and outer sheath simultaneously, but were unable to remove the outer sheath at the stomach because it was entwined with the inner basket wires. As a result, only the duodenoscope was removed, following which a forward-viewing endoscope was inserted along the basket catheter. Using rat-tooth forceps, we grasped, twisted, and pulled the basket wires into the working channel of the scope. Next, we simultaneously pushed the scope to the anal side and pulled the outer sheath to the oral side, dissociating it from the basket wires, so that it could be successfully removed ( Video 1 ). The impaction was subsequently successfully reversed using an emergency mechanical lithotriptor handle (Olympus Medical Systems, Tokyo, Japan).

Therefore, even when using a Trapezoid retrieval basket, basket impaction can occur and an emergency mechanical

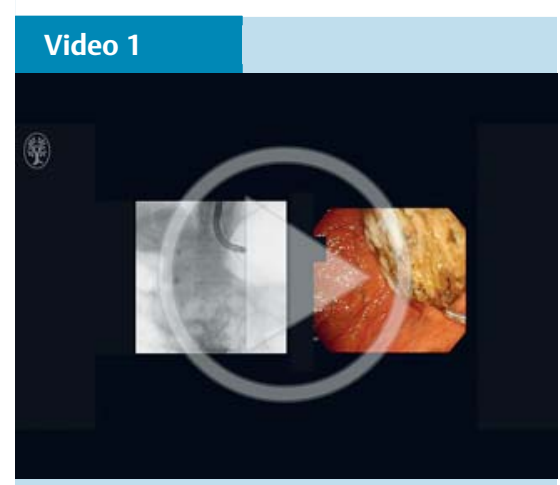

The outer sheath could not be removed as it was entwined with the basket wires. After a forward-viewing endoscope was inserted along the basket catheter, rat-tooth forceps were used to grasp and push the basket wires to the anal side, while the outer sheath was pulled to the oral side; however, adequate traction could not be obtained because the rat-tooth forceps slipped. The basket wires were therefore grasped, twisted, and pulled into the working channel of the scope, which was then pushed to the anal side, while the outer sheath was simultaneously pulled to the oral side (arrows). This successfully dissociated the outer sheath from the basket wires (arrow), so that it could be removed.

lithotriptor handle should be available on standby. Additionally, entanglement between the outer sheath and the inner basket wires can occur because the outer sheath of the Trapezoid is thinner than some other mechanical lithotriptors. The technique described here may be useful in such cases.

\section{Endoscopy_UCTN_Code_CPL_1AK_2AC}

Competing interests: None

Tadahisa Inoue, Kiyoaki Ito, Norimitsu Ishii, Yuji Kobayashi, Masashi Yoneda

Department of Gastroenterology, Aichi Medical University School of Medicine, Nagakute, Japan 


\section{References}

1 Chavalitdhamrong $D$, Donepudi $S, P u L$ et al. Uncommon and rarely reported adverse events of endoscopic retrograde cholangiopancreatography. Dig Endosc 2014; 26: $15-22$

2 ASGE Technology Committee, Adler DG, Conway JD et al. Biliary and pancreatic stone extraction devices. Gastrointest Endosc 2009; 70: $603-609$
Bibliography

DOI http://dx.doi.org/

10.1055/s-0042-117712

Endoscopy 2016; 48: E334-E335

(c) Georg Thieme Verlag KG

Stuttgart · New York

ISSN 0013-726X

\section{Corresponding author}

Tadahisa Inoue, MD

Department of Gastroenterology Aichi Medical University School of Medicine 1-1 Yazakokarimata, Nagakute

Aichi 480-1195

Japan

Fax: +81-561-633208

tinoue-tag@umin.ac.jp 